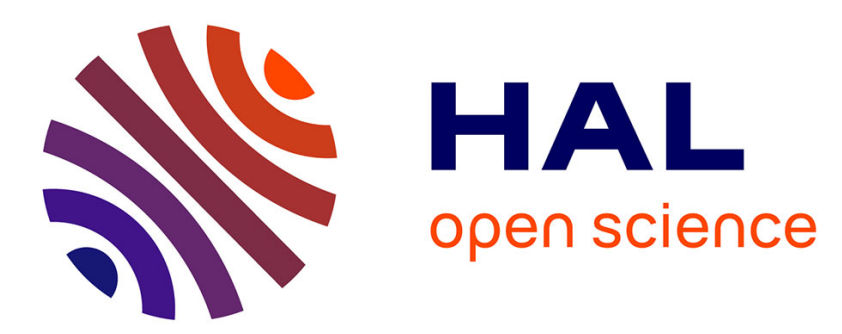

\title{
Graphene: Large scale chemical functionalization by cathodic means
}

Viatcheslav Jouikov, Jacques Simonet

\section{To cite this version:}

Viatcheslav Jouikov, Jacques Simonet. Graphene: Large scale chemical functionalization by cathodic means. Electrochemistry Communications, 2014, 46, pp.132 - 136. 10.1016/j.elecom.2014.06.022 . hal-01072461

\section{HAL Id: hal-01072461 \\ https://hal.science/hal-01072461}

Submitted on 8 Oct 2014

HAL is a multi-disciplinary open access archive for the deposit and dissemination of scientific research documents, whether they are published or not. The documents may come from teaching and research institutions in France or abroad, or from public or private research centers.
L'archive ouverte pluridisciplinaire HAL, est destinée au dépôt et à la diffusion de documents scientifiques de niveau recherche, publiés ou non, émanant des établissements d'enseignement et de recherche français ou étrangers, des laboratoires publics ou privés. 


\title{
Graphene: Large Scale Chemical Functionalization By Cathodic Means
}

\author{
Viatcheslav Jouikov $^{a}$ and Jacques Simonet ${ }^{\mathrm{b} *}$ \\ a) CPM, UMR 6226, Université de Rennes 1, Campus de Beaulieu, 35042 Rennes Cedex,
} France

b) Laboratoire MaSCE, UMR 6226, Université de Rennes 1, Campus de Beaulieu, 35042 Rennes Cedex, France.

\begin{abstract}
Large amounts of graphene were electrochemically functionalized in an adapted frit-separated two-compartment electrolysis cell. The employed technique corresponds to that of a fluidized bed with a dynamic suspension of graphene maintained by an efficient stirring system. A large collector electrode (e.g. a mercury pool or a glassy carbon plate) polarized at a potential adapted to the chemical modification is placed at the center of the cathodic compartment. Modifications are based on two different types of electrochemical reactions: either i) generation of free radicals in situ adding to graphene or ii) the cathodic charge of graphene at the potentials $<-1.8 \mathrm{~V}$ vs. $\mathrm{Ag} / \mathrm{AgCl}$ leading to poly-nucleophilic graphene reactive toward electrophilic reagents present in the solution. Several selected examples underline the interest of this method for building modified graphene materials for further use as deposits on different substrates. The mass modification ratio of graphene could be estimated to be quite high, e.g. one $\mathrm{COOH}$ group per 100 graphene carbon atoms (ca 35 phenyl units).
\end{abstract}

Key words: graphene; modified graphene; redox electrodes; electrolyses.

\section{Introduction}

Glassy carbon (GC) is commonly used an electrode material for carrying out electrolyses, especially in the cathodic domain [1-2]. Until now, a large panel of electro-organic reactions have been easily achieved at negatively polarized carbon. However, when using carbon as the electrode at quite negative potentials $(\mathrm{E}<-1.7 \mathrm{~V})$, one has to take into account its cathodic 
charge. As a mater of fact, although considered for a long time as "inert", glassy carbon contains ribbons of graphite-like structures in discontinuity with "crystallite" boundaries representing all types of unsaturated forms of carbon. This provides extraordinary possibilities for exploiting the reactivity of glassy carbon, which is due to the presence of graphite, fullerene-like structures and graphene formed in this material during its preparation (high temperature pyrolysis of phenolic resins [3-4]). Cathodic charging of these different species is often essential for inducing specific reactions with a large palette of electrophilic reagents (such as alkyl halides carrying redox groups) that are present in the vicinity of the surface [5$6]$.

It also appears essential to consider cathodically charged carbons as a material reactive towards a large number of electrophiles other than alkyl halides. Thus, highly oriented pyrolytic graphite (HOPG), natural graphite from Ceylon, and glassy carbon were reported to react with organic halides and also with carbon dioxide under quite simple and efficient conditions [7-8]. Recent preliminary experiments on the electrochemical modification of glassy carbon, made possible due to the presence of graphite, fullerenes, and possibly of graphene as electroactive impurities, demonstrated deep global modification of this material. Now, the growing interest for functionalization of graphene, quite obviously rich and promising for multiple applications [9], prompts us to consider that charged graphene species may be of high interest for fixing electrophilic compounds such as $\mathrm{CO}_{2}$ [10] under the conditions previously described for other types of carbons.

Experimentally, cathodic polarization of graphene in non-aqueous solvents starts at E $<-$ $1.9 \mathrm{~V}$ vs. $\mathrm{Ag} / \mathrm{AgCl}$ to give a series of cathodic steps described as a globally complex reversible charging rather comparable to that of natural graphite, when deposited onto solid conductor like gold or glassy carbon. Analytically, it was shown that these reduction steps (in close analogy to the chemical charge of graphite) yield a nucleophilic material capable to induce both internal and interfacial reactions. Thus, it is worth recalling that, when polar organic solvents are used, cathodic charge of highly oriented pyrolytic graphite (HOPG) [11] 
specifically leads to well defined insertion stages $\left[\mathrm{C}_{\mathrm{n}}^{-}, \mathrm{TAA}^{+}\right]$via concomitant insertion of electrons and tetraalkylammonium salts (TAAX). Exfoliation of natural graphite by bulky ammonium salts has been reported [12] long before graphene was experimentally prepared. Similarly, such "graphene salts", rather similar to tetraalkylammonium amalgams, could be considered both as reducing species and as poly-nucleophilic materials.

Therefore, modifications of graphene in macro-scale are nowadays important subjects since the development of new modes of addition of different groups (redox, hydrophilic, lipophilic, organo-metallic, etc.) to this material is of great importance. We focused this note on electrochemically induced chemical changes of graphene.

As underlined above and put forward in recent contributions [13], graphene can be seen both as a pro-nucleophilic material and as a radical scavenger, depending on the applied potential and on the nature of reagents present in the solution. We aim to propose here, for the first time, a simple and efficient method for achieving profound chemical functionalizations of graphene in quite large amounts by fixed-potential macro electrolyses using very simple electrolytic cells; the process can further be improved depending on reactions leading to the desired material(s). In this preliminary work, the experimental conditions are restrained to organic polar solvents such as N,N'-dimethylformamide (DMF) containing tetraalkylammonium salts like tetrabutylammonium tetrafluoroborate $\left(\mathrm{TBABF}_{4}\right)$. We point out here the preparation of graphene largely modified with redox entities like ferrocene and anthraquinone, or else with aromatic moieties (anthracene, pyrene, naphthalene) and also with further easily modifiable functions like allyl and propargyl groups. Obviously, this scope is far from being thoroughgoing. Moreover, for the first time we explore the capability of graphene, electrochemically charged in polar organic solvents, to act as a macro-nucleophilic substrate towards carbon dioxide to enable an easy building of [graphene-carboxylate] materials.

\section{Experimental section}


Electrochemical experiments were essentially carried out in $0.1 \mathrm{M}$ solutions of tetraethyl and tetra- $n$-butylammonium tetrafluoroborates $\left(\mathrm{TEABF}_{4}\right.$ and $\left.\mathrm{TBABF}_{4}\right)$, in reagent grade dimethylformamide (DMF). Experiments described in this work needed no special treatment of electrolytic solutions.

Potentials are referred to aqueous $\mathrm{Ag} / \mathrm{AgCl} / \mathrm{KCl}_{(\text {sat) }}$ system. Voltammetric and fixed potential electrolyses were performed using three-electrode cells separated with a fritted glass. The electrochemical instrumentation has been previously reported [14].

Glassy carbon (GC) electrodes used as supports for graphene deposition had geometric area $7 \mathrm{~mm}^{2}$. All glassy carbon samples used as substrates were purchased from Tokai Carbon Co (code: GC Rod). All graphene modifications described in the present note concern a material purchased from XG Sciences as XGnP Graphene Nanoplatelets Grade C. This material typically consists of submicron platelets (particle diameter $<2 \mu \mathrm{m}$, with thickness of a few $\mathrm{nm}$ ). The average surface is of the order of $750 \mathrm{~m}^{2} / \mathrm{g}$ and TEM images permit to detect almost transparent platelets. Oxygen content was reported to be $<2 \mathrm{wt} \%$ while that of carbon $>98.0 \mathrm{wt} \%$.

Macro-modification of graphene were achieved by electrolyses in the presence either of pro-radicals such as $\left\{\pi\right.$-acceptor- $\left.\mathrm{CH}_{2}-\mathrm{Br}\right\}$, often commercially available (Aldrich), or of electrophilic molecules such as substituted organic iodides (the synthesis of Fc- $\left(\mathrm{CH}_{2}\right)_{6}$-I was previously described [14]) and $\mathrm{CO}_{2}$ in saturated solutions in the polar organic solvent (DMF or acetonitrile).

Prior to deposition of the transformed graphene (for building modified electrodes and/or for analysis of the produced functionalized graphene), the electrodes were carefully polished with silicon carbide paper, first with $\{$ Struers 500$\}$ and then with $\{$ Struers 1200$\}$. Then, graphene was mechanically deposited on the GC supports by rubbing the electrodes with pressure against a flat surface (glassy cardboard or polished agate) where graphene is disposed until shiny surfaces were obtained. After using these GC-graphene (GC-GR) 
electrodes, they were rinsed with water and then with acetone followed by final drying in a hot air stream $\left(60^{\circ} \mathrm{C}\right)$.

\section{Results}

\subsection{Macro-electrolyses for graphene modification.}

A typical procedure could be generalized as follows: about $150 \mathrm{mg}$ of graphene are introduced to the cathodic compartment of an H-type electrolytic cell with the available volume of at least $10 \mathrm{~mL}$ (Figure $1 \mathrm{~A}$ ) which was then filled with $6 \mathrm{~mL}$ of DMF containing $\mathrm{TBABF}_{4}$. An efficient stirring permits to form and to maintain graphene suspension similar to a fluidized bed system. The main current collector can be either a mercury pool (convenient when quite negative potentials, $\mathrm{E} \cong-2 \mathrm{~V}$, have to be reached for inducing electrochemical charge of graphene) or a GC plate (about 3-4 $\mathrm{cm}^{2}$ ) placed in the center of the cathodic compartment. The anodic compartment simply contains an anode (carbon, graphite, or platinum grid) immersed in same solvent. Along with graphene, a suitable reagent has to be added to the catholyte (e.g. an electrophile, an RX compound capable to generate free $\mathrm{R}^{\circ}$ radicals within a potential range $>-1.5 \mathrm{~V}$, or else bubbling $\mathrm{CO}_{2}$ to saturation). As underlined in Figure $1 \mathrm{~B}$, the applied potentials may differ according to the mode of modification. In addition, the formation of free radicals from RXs can be catalyzed by deposits of palladium or silver onto the main carbon electrode [13]. Lastly, the electrolyses have to be achieved under inert atmosphere (argon).

Basically, a potentiostatic system is required (to control the potential of the collector electrode). However, with small amounts of electricity injected in this process, a galvanostatic procedure could easily be used as well.

\subsection{Graphene modification by attachment of carbon dioxide and ferrocene.}

a. Grafting of $\mathbf{C O}_{2}$ onto graphene was realized in a $\mathrm{H}$-shaped cell using its saturated solution $(\mathrm{P}=1$ bar, room temperature $)$ in $\mathrm{DMF} / 0.1 \mathrm{M} \mathrm{TBABF}_{4}(8 \mathrm{~mL})$. The amount of graphene charged: $170 \mathrm{mg}$. The electric collector $\left(\mathrm{GC}\right.$ plate, $3 \mathrm{~cm}^{2}$ ) was polarized at $-1.9 \mathrm{~V}$. Under strong stirring, the initial current was $3 \mathrm{~mA}$. After passing $11 \mathrm{C}$ of electricity, the electrolysis 
was stopped; graphene material was filtered off and then rinsed several times with water, then with acetone. The obtained powder of carboxylated graphene was dried for $1 \mathrm{~h}\left(60{ }^{\circ} \mathrm{C}\right)$.

B. Binding ferrocene to graphene was carried out using 1-iodohexyl-6-ferrocene $\left(1.5 \times 10^{-2}\right.$ mol L $\left.{ }^{-1}\right)$ in a similar solution $\left(\mathrm{DMF} / 0.1 \mathrm{M} \mathrm{TBABF}_{4}\right)$. The graphene load was $120 \mathrm{mg}$ and the applied potential ( $\mathrm{GC}$ plate, $4 \mathrm{~cm}^{2}$ ) was $\mathrm{E}=-1.95 \mathrm{~V}$. Total amount of electricity consumed in the process was $4.5 \mathrm{C}$.

$\gamma$. Other modifications: several similar graphene modifications were as well achieved using $\pi$-acceptors bearing $-\mathrm{CH}_{2}-\mathrm{X}$ groups $(\mathrm{X}=\mathrm{I}$ or $\mathrm{Br})$. Upon one-electron reductive cleavage of the $\mathrm{C}$-X end bond of the linker, these precursors lead to $\pi$-acceptor- $\mathrm{CH}_{2}{ }^{\bullet}$ radicals. For example, 2-bromomethyl-anthraquinone was successfully used to attach anthraquinone groups onto graphene. The same procedure was used for efficient grafting of other benzyl-type systems including pyrene, naphthalene, anthracene, and other substituted aromatics. Similarly, allylic and propargylic offshoots were successfully grafted to graphene, both groups being easily chemically modifiable to allow various ensuing functionalizations of this material. Typically, mercury and GC macro-electrodes were used, and applied potentials were $>-1 \mathrm{~V}$. Arbitrarily, we chose to limit the electricity consumption per mass of graphene present in the cell (actually about 5 coulombs per $100 \mathrm{mg}$ of graphene).

\subsection{What is the average level of grafting by means of the proposed procedure?}

This is a question difficult to solve in the absence of a marker. In this preliminary approach, we opted for the use of redox markers such as anthraquinone (AQ), ferrocene (Fc), 4-nitrophenyl, 4-cyanophenyl, 4-iodophenyl and other groups providing a distinct redox response. In the case of carboxylated graphene, additional post-grafting transformations of the $-\mathrm{CO}_{2} \mathrm{H}$ group were achieved (e.g. easy addition of anthraquinone).

Main results (with $\mathrm{CO}_{2}, \mathrm{AQ}$, and $\mathrm{Fc}$ ) are displayed in Figure 2. The working principle is the same in all cases: the deposition of modified graphene (typically from 0.15 to $0.5 \mathrm{mg}$ ) in fine layers onto a GC plate (average area from 0.5 to $1 \mathrm{~cm}^{2}$ ) followed by the integration of the global redox response of the GC coverage used as electrode. Several measurements (with 
different amounts of modified graphene) allowed us to check that electrochemical signals remain proportional to the deposited mass. Under the experimental conditions summarized above, the attachment of Fc corresponds to $(5 \pm 2) \times 10^{-4} \mathrm{Fc}$ per graphene carbon atom while that of AQ (using AQ- $\left.\mathrm{CH}_{2}-\mathrm{Br}\right)$ similarly exhibits the levels of $(5 \pm 1) \times 10^{-4} \mathrm{AQ} /$ carbon. Modification by $\mathrm{CO}_{2}$ (quantified via its subsequent transformation in the AQ-tagged material) appears quite efficient and corresponds to $\approx 10^{-2}$ carboxylate groups per carbon. Experiments with much larger amounts of electricity remain to be done to produce more extensively modified graphenes.

\section{Conclusion}

Macro-electrolyses performed with graphene in fluidized bed mode in the solutions of DMF or ACN containing tetraalkylammonium salts lead to chemical modifications of graphene in a large amount. These functionalizations are exemplified with extensive carboxylation and with grafting of redox moieties like anthraquinone, ferrocene, nitrophenyl, etc. Experimental conditions of this process are very simple and could be applied, after deposition of modified graphenes onto conducting solid supports (glassy carbon, metals like gold, palladium, platinum, and silver) to a wide variety of modified electrodes usable in catalysis and analysis.

\section{References}

[1] R. L. McCreery, Chem. Rev., 108 (2008) 2646.

[2] D.G. Peters, in: H. Lund, O. Hammerich (Eds.), Organic Electrochemistry, M.M. Dekker, New York, Basel, (2001) 341.

[3] G. M. Jenkins, K. Kawamura, Nature, 231 (1971) 175.

[4] P. J. F. Harris, Philosophical Mag., 84 (2004) 3159.

[5] V. Jouikov, J. Simonet, Electrochem. Comm., (2014) http://dx.doi.org/10.1016/j.elecom.2014.05.015 and refernces quoted therein.

[6] D. Lorcy, K-S Shin, M. Guerro, J. Simonet, Electrochim. Acta, 89 (2013) 784. 
[7] G. Bernard, J. Simonet, J. Electroanal. Chem., 112 (1980) 117.

[8] C. Dano, J. Simonet, J. Electroanal. Chem., 564 (2004) 115.

[9] L. Dai, Acc. Chem. Res., 46 (2013) 31.

[10] J. Simonet, Electrochem. Commun., 21 (2012) 22.

[11] J. O. Besenhard, Carbon, 14 (1976) 111.

[12] J. Simonet, H. Lund, J. Electroanal. Chem., 77 (1977) 719.

[13] V. Jouikov, J. Simonet, Electrochem. Commun., 42 (2014) 34.

[14] V. Jouikov, J. Simonet, Langmuir, 28 (2012) 931.

\section{Captions for Figures}

\section{Figure 1}

Conditions and chemical reactions of electrochemical modification of graphene.

(A) Electrolysis setup for in situ grafting of graphene. (B) Schematic representation of two potential-dependent modes of graphene modification via radical $\left(\mathrm{B} 1\right.$ : addition of $\mathrm{R}^{\bullet}$ produced by reduction of a soluble radical precursor) and nucleophilic (B2: transforming graphene into a poly-nucleophilic material) mechanisms. (C) Nyquist plots (inset: voltammetry) of the reduction of tetracyanobenzene (TCB) at modified graphene layers deposited on GC electrodes. (a) GC-GR-CH 2 -pyrene interface; $\mathrm{R}_{\mathrm{CT}}=780$ kohm. (b) GC-GR-COOH interface; $\mathrm{R}_{\mathrm{CT}}=7.5 \mathrm{kohm}$. (c) Bare GC. Solvent: $\mathrm{CH}_{3} \mathrm{CN} / 0.1 \mathrm{M} \mathrm{Bu}_{4} \mathrm{NPF}_{6} . \mathrm{E}=-0.7 \mathrm{~V}, \Delta \mathrm{E}=10 \mathrm{mV}$. Frequency range: from $250 \mathrm{kHz}$ to $0.01 \mathrm{~Hz}$. (D) Reflectance FTIR spectra of GC-supported graphenes modified with: (a) $-\mathrm{CO}_{2} \mathrm{H}, 3300-2800 \mathrm{~cm}^{-1}\left(\mathrm{H}_{2} \mathrm{O}, v_{\mathrm{O}-\mathrm{H}}\right.$, edge $\mathrm{C}-\mathrm{H}$ of graphene), $1780 \mathrm{~cm}^{-1}\left(v_{\mathrm{C}=\mathrm{O}}\right), 1430,1170 \mathrm{~cm}^{-1}\left(v_{\mathrm{C}-\mathrm{O}}, \delta_{\mathrm{C}-\mathrm{H}}\right), 950 \mathrm{~cm}^{-1}\left(\delta_{\mathrm{O}-\mathrm{H}}\right) .(\mathrm{b})$ Anthraquinone, $3100-$ $2900 \mathrm{~cm}^{-1}\left(v_{\mathrm{C}-\mathrm{H}}\right), 1710-1610 \mathrm{~cm}^{-1}, 1330-1300 \mathrm{~cm}^{-1}\left(v_{\mathrm{C}=\mathrm{O}}, v_{\mathrm{C}=\mathrm{C}}\right.$ and $\left.v_{\mathrm{C}-\mathrm{C}}\right), 930,700 \mathrm{~cm}^{-1}\left(\delta_{\mathrm{C}-\mathrm{H}}\right)$. (c) $\left.-\mathrm{SO}_{2} \mathrm{C}_{6} \mathrm{H}_{4} \mathrm{NO}_{2}, 3140-3060\left(v_{\mathrm{C}-\mathrm{H}}\right), 1530 \mathrm{~cm}^{-1}\left(v_{\mathrm{N}=\mathrm{O}}\right), 1360 \mathrm{~cm}^{-1} v_{\mathrm{C}-\mathrm{N}}\right)+1350 \mathrm{~cm}^{-1}$ $\left.\left(v(\mathrm{as})_{\mathrm{S}=\mathrm{O}}\right), 1160 \mathrm{~cm}^{-1} v(\mathrm{sym})_{\mathrm{S}=\mathrm{O}}\right), 810 \mathrm{~cm}^{-1}\left(\delta_{\mathrm{C}-\mathrm{H}}\right) .(\mathrm{d})-\left(\mathrm{CH}_{2}\right)_{6} \mathrm{Fc}, 1480,1380 \mathrm{~cm}^{-1}\left(\delta_{\mathrm{C}-\mathrm{H}}, \mathrm{Fc}\right)$; $1100 \mathrm{~cm}^{-1}, \mathrm{C}-\mathrm{H}$ wagg. $(\mathrm{Fc}), 820 \mathrm{~cm}^{-1}\left(\delta_{\mathrm{C}-\mathrm{H}}, \mathrm{CH}_{2}-\mathrm{Fc}\right)$. 


\section{Figure 2}

Redox responses of modified graphenes deposited onto GC surfaces. Cycling in DMF/0.1 M $\mathrm{TEABF}_{4}$. Scan rate: $50 \mathrm{mV} \mathrm{s}^{-1}$. For experimental conditions, see the text.

(A) and (B): Graphene (120 mg) modified by $\mathrm{Br}-\mathrm{CH}_{2}-\mathrm{AQ}\left(15 \mathrm{mmol} \mathrm{L}^{-1}\right)$. Potential: $-0.7 \mathrm{~V}$. Amount of electricity: 4.5 C. Collector electrode: GC plate $\left(4 \mathrm{~cm}^{2}\right)$. Deposition onto a GC $\operatorname{disk}\left(7 \mathrm{~mm}^{2}\right)$ of $<0.03 \mathrm{mg}$ and deposition of $0.16 \mathrm{mg}$ onto smooth GC plate $\left(0.8 \mathrm{~cm}^{2}\right)$, respectively.

(C) Modification with Fc- $\mathrm{C}_{6}$ - $\mathrm{I}\left(15 \mathrm{mmol} \mathrm{L}^{-1}\right)$. Use of an $\mathrm{Hg}$ pool, area: $4.5 \mathrm{~cm}^{2}$. Amount of graphene: $75 \mathrm{mg}$. $\mathrm{E}=-1.74 \mathrm{~V}$. Amount of electricity passed: $2.7 \mathrm{C}$.

(D) Modification of graphene $(170 \mathrm{mg})$ with $\mathrm{CO}_{2}$ (saturated in DMF at $\left.25^{\circ} \mathrm{C}\right)$. Collector electrode: GC plate, $3 \mathrm{~cm}^{2}$. Applied potential: $-1.9 \mathrm{~V}$. Amount of electricity: $11.0 \mathrm{C}$. Deposition of carboxylated graphene $(0.15 \mathrm{mg})$ onto a GC plate $\left(1 \mathrm{~cm}^{2}\right)$. Modification of carboxylate group by $\mathrm{Br}-\mathrm{CH}_{2}-\mathrm{AQ}$. 


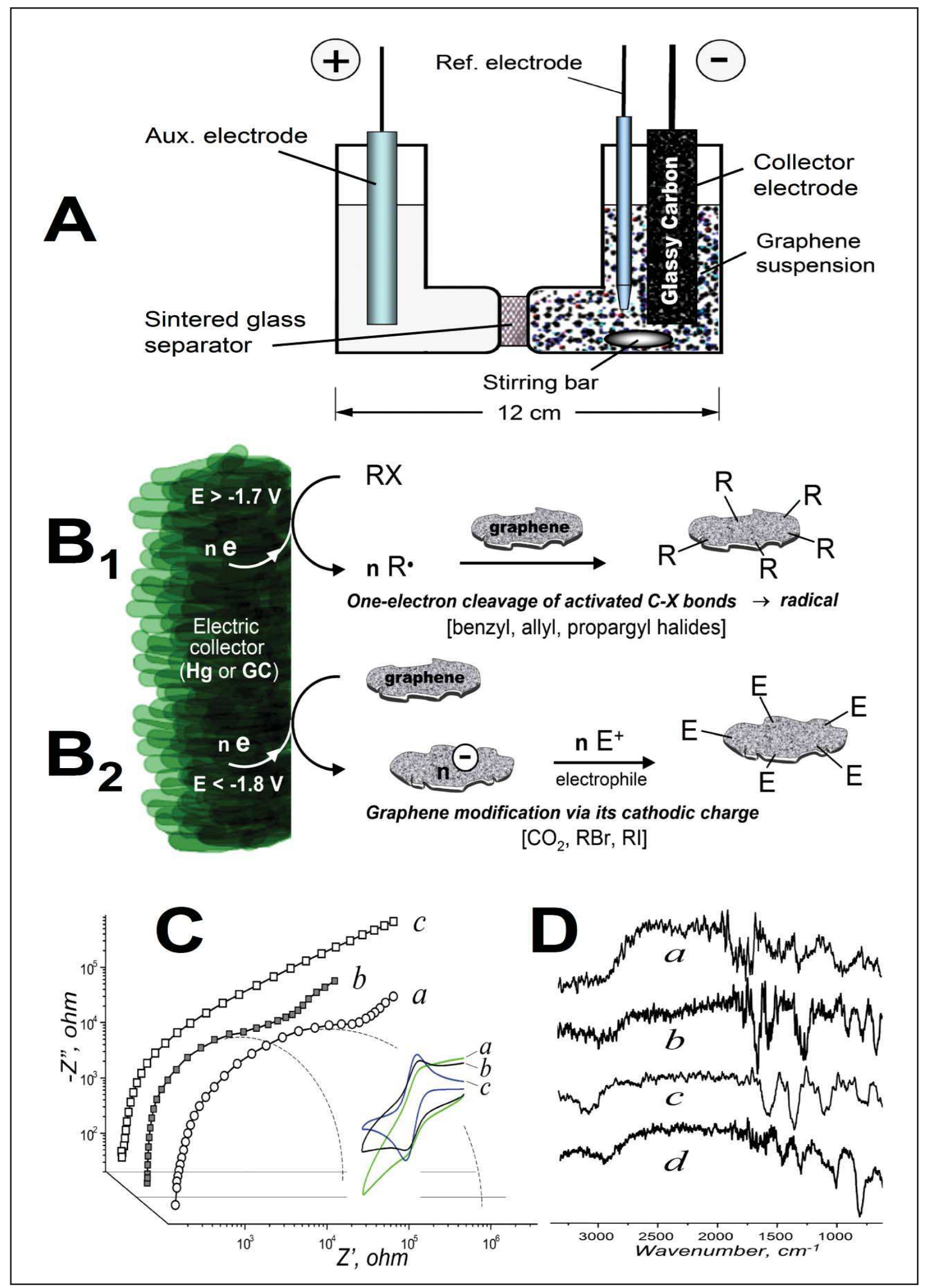

Figure 1 

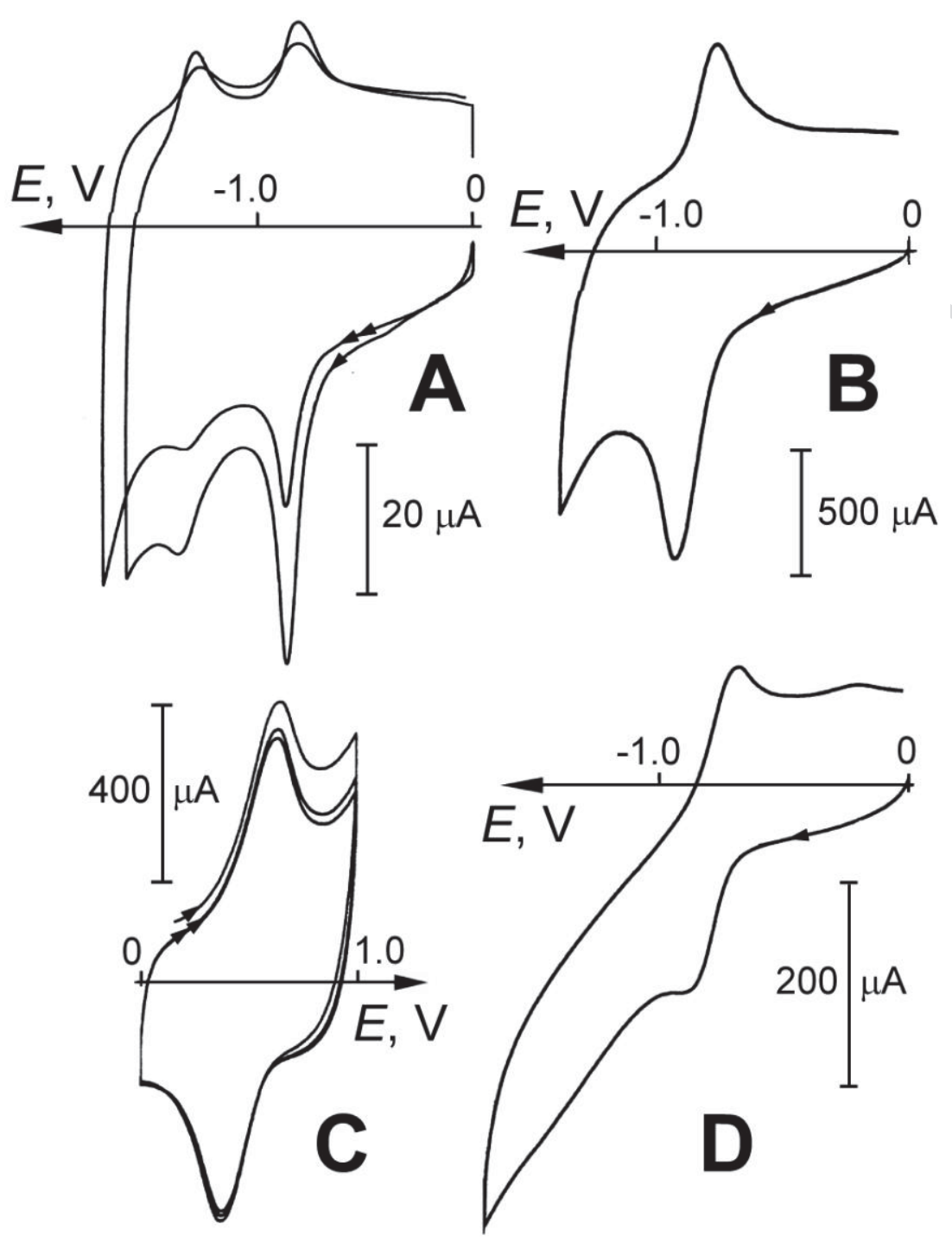

Figure 2. 


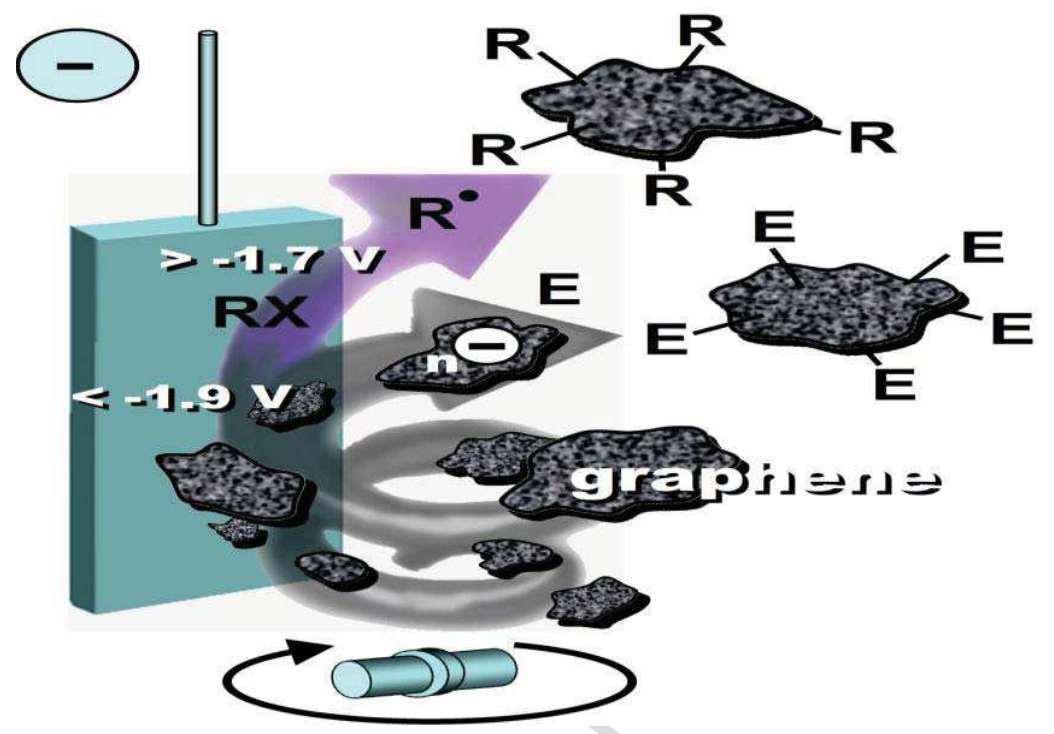

Graphical abstract 


\section{Highlights}

Reduction of graphene nanoplatelets in polar aprotic solvents $>$ Electrolysis to afford a cathodic charge of graphene in suspension $>$ Generation of a polynucleophilic form of graphene reacting with organic nucleophiles $>$ Alternative addition of electrogenerated radicals onto graphene depending on applied potential. 